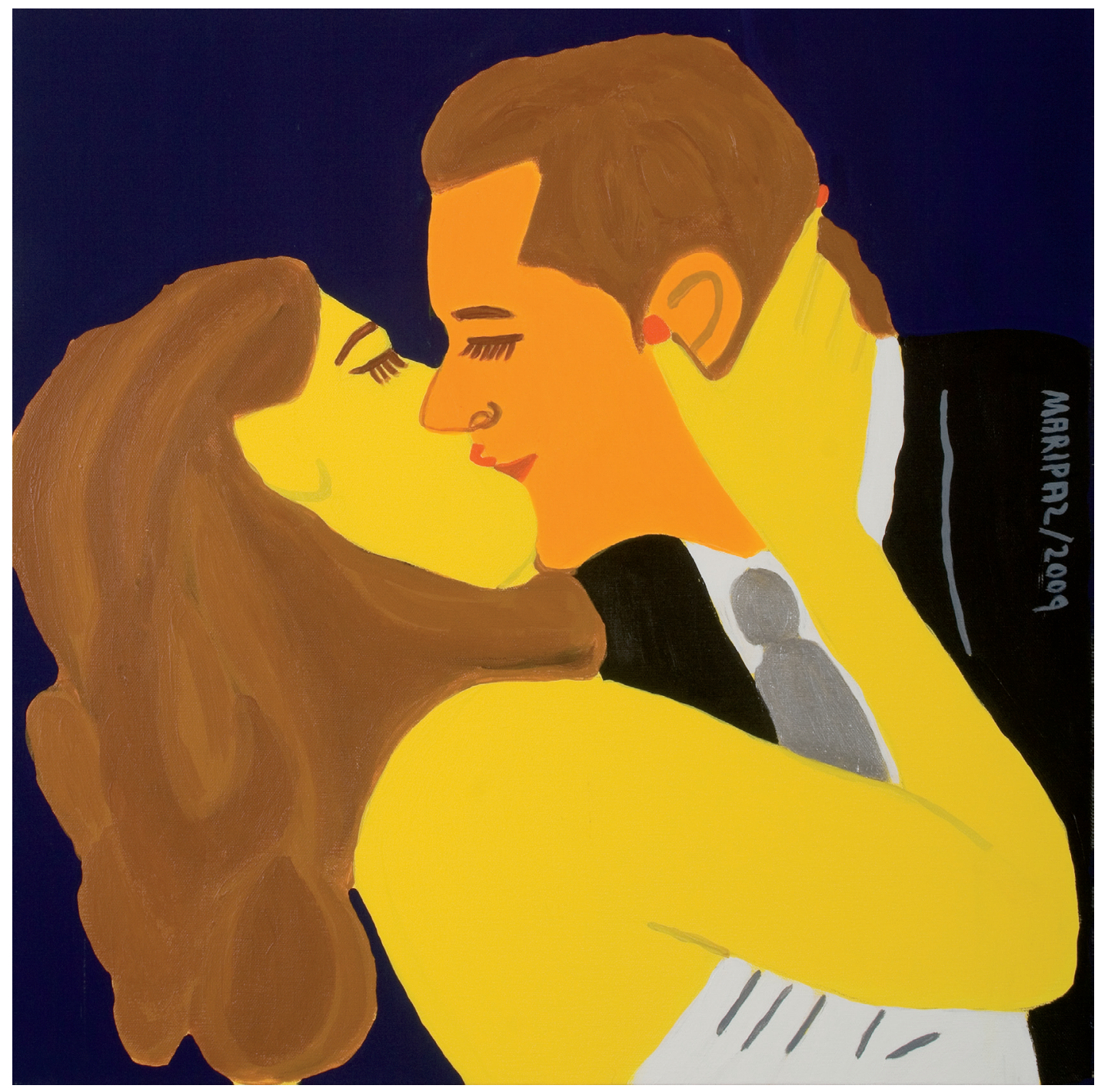

Serie Bailando por un sueño. No.1 


\title{
La flexibilidad estricta en la Lectura y la Escritura
}

\author{
Fecha de recepción: 14 de enero de 2011 - Aceptación: 26 de febrero de 2011
}

\section{Constanza Rodríguez Barón}

\section{Resumen}

Este artículo plantea la necesidad de darle más importancia a la lectura y escritura en todos los contextos académicos. Para este fin, los primeros que tenemos que involucrarnos en estas prácticas, que posteriormente serán transmitidas a los estudiantes, somos los maestros. Por otra parte, el artículo pretende hacer reflexionar a los docentes que en los colegios y pregrados no aprovechan el interés que los estudiantes tienen en la tecnología y no los guían en su uso como herramienta para fomentar la lectura. Por último, cuestiona la exclusión, que en algunos casos, las instituciones educativas ponen en práctica al no tener en cuenta la heterogeneidad de bagaje e intereses de lectura y escritura con que llegan los estudiantes.

\section{Abstract}

This article brings up the necessity to give more importance to the reading and writing abilities in all academic contexts. For this purpose, we, as teachers, must set an example by committing ourselves to these practices that can be transmitted later on to our students. On the other hand, the article is intended to make school and university teachers reflect on the need to take advantage of students' interest in technology as a tool to promote reading. Finally, it questions the exclusion that, in some institutions, is evident when the students' heterogeneity in reading and writing interests and backgrounds is not taken into account.

\section{Palabras claves}

Lectura, escritura, heterogeneidad, academia, realidad, flexibilidad, formación, crítica

\section{Key words}

Reading, writing, heterogeneity, academy, reality, flexibility, education, critical thinking.

\section{"Dicen que soy un gran escritor. Agradezco esa curiosa opinión, pero no la} comparto. El día de mañana, algunos lúcidos la refutarán fácilmente y me tildarán de impostor o chapucero o de ambas cosas a la vez".

Jorge Luis Borges

¿Estamos perdiendo la capacidad de escribir y expresar con profundidad nuestras ideas, o estamos cayendo en la pereza de no pensar? ¿Estamos transmitiendo en la Escuela esta incapacidad y esta pereza a los estudiantes, quienes, a su vez, sorprenden y desilusionan a los docentes?

Quejas y preocupaciones hay por montón y de toda índole: 
"Resulta alarmante para los docentes de la Escuela Media observar que alrededor del 75\% de sus alumnos escriben con letra de imprenta y aún más lamentable descubrir que muchos de ellos no saben hacerlo de otra forma". (Susana B. González, profesora de Enseñanza Media y Superior en Letras. 2008)

"Hemos tenido ya décadas de cursos de composición en los que los estudiantes intercambian opiniones banales sobre los temas de interés del momento, y la escritura estudiantil se ha vuelto cada vez peor. ¿No tiene sentido pensar que si se les está intentando enseñar a utilizar las formas lingüísticas, las formas lingüísticas son lo que se debería enseñar?” (Stanley Fish, profesor y escritor del New York Times. 2006)

"Parece que cada ensayo y examen en casa es una invitación para usar Google. Luego, el proceso es tan simple como "cortar y pegar," usualmente de Wikipedia, pero si se es más creativo, de entre los primeros 10 resultados. Algunos estudiantes no se preocupan siquiera de cambiar el tipo de letra o el formato. ¡Algunos copiaron mis propios trabajos!” (Ewa Wasilewska, Salt Lake Tribune, 2009)

"Si la Universidad no produce escritura es una Universidad muerta; mejor dicho, no

\section{Reseña de autor \\ Constanza Rodríguez Barón (Colombia) \\ Politécnico Grancolombiano \\ corodrig@poli.edu.co}

Egresada de la Facultad de Lenguajes y Estudios Socioculturales de la Universidad de Los Andes. Es candidata al título de Maestra en Educación, con énfasis en didáctica del inglés, de la Universidad Externado de Colombia. Desde 1995, año en que recibió su título como profesional en Lenguas Modernas, se ha dedicado a la docencia universitaria. Trabajó en la Universidad Javeriana, Los Andes y, actualmente, es profesora de tiempo completo del Departamento de Idiomas de la Universidad Politécnico Grancolombiano. Participó como investigadora y conferencista durante dos años en el proyecto de investigación Aprender a aprender de la Universidad de Los Andes. existe como tal. La razón es muy sencilla: es el gran escenario de construcción, circulación, discusión y puesta en práctica del conocimiento. Y para alcanzar tales propósitos se debe investigar. Luego, para investigar hay que leer y escribir". (Armando Montealegre, profesor de Pedagogía y Literatura. 2006)

\section{Vacíos y trasfondo}

El tema de la escritura preocupa a eruditos, defensores de la lengua, profesores y algunos estudiantes "comprometidos" con la academia. Sin embargo, no se ha alcanzado un consenso con relación a lo que el término encierra, a lo que implica escribir textos académicos, a las competencias lingüísticas que se deben desarrollar, a los temas que pueden ser considerados académicos o a la audiencia para la cual se escribe o se debe escribir.

En cuanto al término, en lo único en que se puede coincidir es que la escritura es una forma de comunicación del hombre, y es precisamente por esto que formalizarla o tipificarla puede llegar a ser un acto de rigidez que va en contra de la variedad humana. La escritura, en términos de Ricoeur, nos permite plasmar nuestra "experiencia íntima de tiempo (tiempo vivido) en el tiempo físico“ Ricoeur (1987, p.46), o como lo decía Barthes (1953) en El Grado Cero de la Escritura“. La escritura se impregna de quien escribe, de su historia, su pasado, su biología... Por lo cual, se puede hablar de tantos estilos como los hay escritores, experiencias, vidas. Pero ¿qué pasa cuando no hay ni estilos, ni escritores, ni la intención de formarlos en la academia?

A los estudiantes seles dificulta llevar a cabo procesos básicos de lectura y escritura como discernir, interpretar, organizar y expresar con claridad ideas, argumentar o pensar en el registro o carácter de sus textos. Para la mayoría, 
resulta igual escribir un resumen, un ensayo o una reseña, y muchos se limitan a escribir de la misma forma en que hablan. De esta manera, van perdiendo la capacidad de abrirse a los otros, a la otredad. (Petit, 2003) más aún si tenemos en cuenta que como bien lo expresa Seco "El lenguaje es el gran instrumento de comunicación de que dispone la humanidad...el que se expresa con mayor claridad y precisión, es dueño de recursos poderosos para abrirse camino en su trato con sus semejantes". (Seco, 1973, p.86). Sin embargo, estas dificultades no son gratuitas, los estudiantes no se vuelven perezosos de un día para otro, para escribir. Ellos vienen con una carencia lectoescritora desde sus colegios.

De hecho, desde hace más de 10 años, el Ministerio de Educación Nacional de Colombia, preocupado por la drástica disminución en los índices de lectura registrados por organismos nacionales e internacionales (Dane, Unesco, Ocde), adelanta un programa de actualización docente junto con la Escuela de Ciencias del Lenguaje de la Universidad del Valle y el Icetex. En las etapas de caracterización de este programa, los docentes han reconocido que no leen o leen muy poco y que no están preparados y/o motivados para escribir.

Esto reduce entonces el número de oportunidades que se les brinda a los estudiantes en los colegios y universidades para desarrollar escritura argumentativa. Los docentes, escudándose en su falta de tiempo, preparación o motivación no la fomentan o se limitan a evaluar compresión por medio de resúmenes, donde el ejercicio de organización de ideas, inferencia y argumentación es muy reducido o inexistente.

Los estudiantes, entonces, se acostumbran a este tipo superficial de escritura o a argumentar, como lo hacen oralmente. De hecho,
(Caravallo,1998) a propósito de una investigación hecha con textos de estudiantes de primer semestre de la Universidad de Misiones, Argentina, asegura: "Los estudiantes no se preocupan por su receptor, suponen de antemano que cuentan con su colaboración; no se proponen exhaustividad o claridad; escriben lo que pueden, lo que les “sale". Además se advierte la escritura espontánea, sin preocupaciones por la prolijidad o legibilidad, frecuente en situaciones de aprendizaje o evaluación".

Así las cosas, si los jóvenes llegan con esa idea de que escribir formalmente implica sólo resumir y que para argumentar se recurre al mismo lenguaje informal cargado de elipsis, descripciones, conjunciones, muletillas o repeticiones, como el que usan al hablar. Su paso por la universidad debería significar un "desaprender" y volver a aprender a escribir de forma académica. Lo anterior se lleva a cabo teniendo en cuenta que "para transmitir un mensaje de forma comprensible para otros, es decir, para comunicarse con los demás, es necesario dominar los principios, las reglas y, en general, el arte del lenguaje escrito y de la redacción académica, cuyas peculiaridades se relacionan sin rodeos con su objetivo, a saber, con la comprensión exacta del mensaje transmitido. Este arte se domina precisamente en el empeño consciente de lograrlo". (Alfonso, 1999, p-56).

Sin embargo, las universidades están descuidando el desarrollo de la habilidad de comprensión, interpretación y producción de textos. El objetivo es "llenar" a los estudiantes, como si fueran recipientes, de teorías relacionadas con su área de especialización, sin permitirles o exigirles profundizar en ellas y argüirlas de manera formal.

Respecto a esta falta de competencia para
A los estudiantes se les dificulta

llevar a cabo procesos básicos de lecturay escritura como lo son discernir, interpretar, organizary expresarcon claridad ideas, argumentar opensar en el registro o carácter de sus textos. 
el manejo de textos, Becerra (1999) explica que desde el modelo de Sujeto Completamente Alfabetizado (SCA) se necesitan diferentes niveles de alfabetización para llevar a cabo cualquier actividad, no sólo académica, sino también social. El SCA es "aquel que dispone de la competencia necesaria para discriminar y manejar diferentes tipos de texto, para fortalecer acciones, sentimientos y pensamientos con un propósito específico, en un contexto social determinado". (Wells, 1989, citado por Becerra, 1999, p-15).

\section{Balcance de las falencias}

¿Qué pasa entonces cuando un estudiante con esta carencia llega a contextos laborales o universitarios formales y se ve enfrentado a la necesidad de producir textos académicos para sus colegas, con propuestas interesantes, argumentos contundentes y lenguaje "apropiado? Es posible que ni siquiera sea conciente de sus vicios y fallas y continúe con su escritura caótica, cándida y poco profunda. A pesar de que sus ideas sean válidas y sus argumentos relevantes, un escrito desordenado, con errores de gramática y ortografía o con vocabulario pobre le quitará credibilidad y seriedad al contenido.

La otra tendencia a la hora de querer parecer formal es el plagio. Sorprendentemente, este fenómeno se presenta en todos los niveles educativos, algunas veces por pereza o falta de lenguaje e ideas y otras, simplemente por desconocimiento. Muchos estudiantes y profesionales no saben con certeza lo que representa plagiar. Ingenuamente, creen que con el hecho de cambiar algunas palabras ya se hacen dueños de las ideas, y truncan así su potencial para pensar y producir. Sin embargo, ese deseo, en ocasiones falso, de parecer un creador de nuevas ideas es muchas veces la causa de apropiación del conocimiento de otros. Los estudiantes no citan sus fuentes porque consideran, erróneamente, que al acudir a muchas citas, hacen evidente su incapacidad para producir. Esta creencia nos debe llevar a reflexionar sobre lo que, hoy en día, implica crear.

Ya no estamos en el siglo XVIII, en el oportuno siglo de las luces que sacó a la humanidad del oscurantismo y la ignorancia en que estaba sumida. Siglo en el que la razón iba de la mano de nuevos descubrimientos y nuevas teorías cuya difusión se hacía a través de textos a los cuales no era fácil para cualquiera tener acceso. Muchos años han pasado y mucho se ha dicho. Hoy en día, el primer paso entonces para producir es conocer lo que ya está creado, analizado, pensado, discutido, probado, descartado. La tecnología nos abre las puertas de este casi infinito mundo del conocimiento que no se puede desaprovechar. Como tampoco se puede ignorar la realidad de nuestro país en términos de lectura. En el texto Las Tramas de la cultura, Germán Rey nos expone cifras alarmantes sobre este tema en Colombia. De hecho, la única estadística esperanzadora es la lectura en Internet, que en el periodo del 2000 al 2005 pasó del 5\% al 11\% y la tendencia ha seguido siendo el aumento, especialmente entre los jóvenes de 12 a 17 años.

Sin embargo, en este punto hay dos cuestiones que se deben mirar de cerca. En primer lugar, las instituciones educativas no tienen en cuenta estas tendencias y no enseñan a los estudiantes a aprovechar esas puertas abiertas. Se les permite o se les promueve entrar a esta gran biblioteca de la humanidad, pero no se les guía en su manejo y respeto por lo que allí encuentran. En segundo lugar, hay investigaciones que han demostrado que: "La red es una tecnología de búsqueda, no de lectura" (Galina, 2002) pero esto no significa que la función de Internet sea siempre pro- 
mover la pereza mental y dominar las masas. Se ha desvirtuado tanto su uso que algunos profesores prefieren mantenerse alejados de ella, sin darse cuenta de que con esto también se alejan de sus estudiantes, y de sus formas de socializar y conocer el mundo.

Ante estas realidades, los maestros debemos encontrar las posibilidades y aprovecharlas. La gran ventaja de estas puertas que abre Internet es la posibilidad de conocer precisamente todo eso que se ha dicho en nuestra(s) área(s) de interés. El gran reto del que la institución debe apropiarse es el de guiar a sus estudiantes para poner todo este conocimiento en perspectiva; es decir, poder ver con claridad los diferentes puntos de vista que le dieron origen o que se desprenden deél. De esta forma, los estudiantes podrán relacionar teorías, compararlas, entender su relevancia, y proponer, a partir de ellas, nuevos conceptos, nuevas visiones, relaciones. Y esto en el siglo XXI, el siglo de las TICs, es construcción de conocimiento.

Sin embargo, la formación de individuos críticos que estén en capacidad de adaptar, modificar o crear conocimiento requiere de amor y respeto hacia la lectura y la escritura por parte de quien educa, para consecuentemente transmitirlo a los estudiantes. Desafortunadamente, nuestra realidad social y académica muestra lo contrario: desinterés y ligereza hacia la práctica de la lectura. Según investigaciones del Dane: " $52,40 \%$ de las personas de 12 años y más que saben leer y escribir dicen haber leído libros (un 47,60 \% no lee libros). El 47,09\% ha leído aunque sea una revista y el 57,03\% dice haber leído un periódico, en el último mes. En conclusión, la mitad del país no lee nada". (Consumo cultural, clave. Martín Barbero en Lecturas El Tiempo, Mayo 2009).
En otras estadísticas presentadas por la Cámara Colombiana del libro y ampliamente analizadas por Eduardo Bechara en su artículo de El Tiempo.com titulado: Colombia: ¿Un País de Lectores?, "el promedio de libros leídos por un colombiano al año bajó de 2.4 en 2000 a 1.6 en 2005, una cifra mínima si hablamos de un país que quiere salir del atraso. Nuestro promedio es inferior en relación a otros países latinoamericanos como México 2.5, Argentina 3.2, o Brasil 3.3, y parece ínfimo comparado con España 7.7, o Francia, en donde alguien que lea menos de diez libros al año es considerando un lector débil”. (Bechara, 2009) ¿Y qué generan estas estadísticas en la academia? ¿Lamentaciones o iniciativa y afán para cambiar esa realidad?

Es claro, que aunque todos hagamos parte de esos porcentajes, nuestros intereses, motivaciones, experiencias y conocimientos son distintos. Dehecho, en cualquier contexto socialy académico, por pequeño que sea, la diferencia es la constante. Depende entonces, de la academia aprovechar esta heterogeneidad y variedad de saberes para generar debate, para ayudar a todos los estudiantes, sin excluir o desmotivar, a encontrar la forma de ampliar y canalizar sus conocimientos. Esto no tendría por que ser tan difícil si la educación se flexibiliza y, como dice el maestro Martín Barbero se tiene en cuenta que: "La autonomía del lector depende de una transformación de las relaciones sociales que sobredeterminan su relación con los textos. La creatividad del lector crece a medida que decrece el peso de la institución que la controla”. (Martín Barbero, 2002, p.329)

Ahora bien, tener en cuenta la heterogeneidad implica asumir la realidad de que hay estudiantes que hasta ahora se inician formalmente en la lectura y su permanencia en esta práctica depende del amor que le tomen;
... la formación de individuos críticos que estén en capacidad de adaptar, modificar o crear conocimiento requiere de amor y respeto hacia la lectura y la escritura por parte de quien educa, para consecuentemente transmitirlo a los estudiantes. 
como bien lo afirma el periodista colombiano Daniel Samper “...para leer se necesita voluntad y afición". (Samper, 2010). Por esta razón, iniciarlos con lecturas de textos demasiados académicos puede empezar a crear una barrera. La lectura debe ser, como lo propone Martín Barbero, más autónoma y variada. Se le puede presentar al estudiante una amplia bibliografía del tema que le permita aproximarse a él con libertad.

Como muchos académicos y grandes pensadores lo han expresado, no hay nada más placentero que adentrarse en un libro que se entienda, con el que se logre cierto grado de identificación. Esa es la lectura que realmente aporta. Ya lo decía Knight en 1896: “...sólo es posible difundir conocimiento útil si también se entretiene a los lectores", o en palabras de Freire: "La lectura se inicia con la curiosidad. Los textos son objetos a develar, de los que es posible aprender una significación profunda y personal que hará posible finalmente la memorización y la fijación sin ser éstas impuestas por el docente". (Freire, 1991, p.24). Al respecto también podemos citar a Deleuze quien expone la posibilidad de: "considerar un libro como una máquina asignificante cuyo único problema es si funciona y cómo funciona, ¿ cómo funciona para ti? Si no funciona, si no tiene ningún efecto, prueba a escoger otro libro". (Deleuze, 2011) Y en este punto no tendría que presentarse ningún problema ya que en toda área de conocimiento hay gran variedad de autores, puntos de vista o enfoques, que, en cualquiera de los casos, amplían nuestra visión y realidad.

De forma casi paralela y simultánea, el estudiante se puede sentir motivado a combinar eso que ya sabe, a través de sus vivencias o de su intuición, con los conocimientos más formales que va adquiriendo por medio de la lectura. Puede sentir el deseo de producir, él mismo, teorías o simples hipótesis a través de esa combinación de saberes. Si está disfrutando y viviendo la lectura, nuevas preguntas y dudas necesariamente surgirán. De manera espontánea, entonces, puede empezar a plasmar estos interrogantes en ensayos, y buscar la forma de aclararlos a través de la investigación. Es una cuestión de aprovechar lo que los estudiantes ya poseen: motivación, conocimientos valiosos y deseo de ahondar en ellos; saber fomentar aquello que les puede hacer falta: habilidades investigativas; y motivarlos a canalizar esto con lo que ya cuentan y lo que van adquiriendo de manera espontánea, pero sistemática.

Para alcanzar este objetivo, como se ha planteado anteriormente, el tema de la flexibilidad "estricta” es fundamental. ¿Qué es esta contradicción de flexibilidad estricta? En una universidad se puede y se debe exigir rigor en cuanto a la disciplina y sistematización de la lectura y la escritura para acercarnos a lo que proponían desde el siglo XIX los estilistas franceses, L. Veuillout (formar escritores claros o incluso elegantes a través del trabajo) y Antoine Albalat (crear talento). (Albalat, 1961, p.16).

Sin embargo, por otro lado, se debe ser flexible cuando de textos, autores y temas se trata. ¿Quién dijo que sólo la lectura de autores reconocidos en comunidades científicas o académicas es la que amplía conocimientos y visiones? ¿Por qué creemos o intuimos que entre más complicado sea el tema, más elaborado el lenguaje y menos accesible la escritura, estamos siendo más intelectuales? ¿Qué estamos entonces buscando en la academia: inclusión o exclusión? Estos son interrogantes que no podemos ignorar los que, de alguna u otra manera, estamos dentro de este proyecto de formar. 
Después de estas reflexiones, volvamos ahora a las dos preguntas iniciales y para darles respuesta: $¿$ Estamos perdiendo la capacidad de escribir y expresar con profundidad nuestras ideas, o estamos cayendo en la pereza de no pensar? No estamos perdiendo nuestra capacidad de expresarnos, pero sí la estamos modificando. Recordemos que, como Derrida (1998) lo expone en su Lingüística y Gramatología, la escritura no se puede desligar de la historia, del devenir de la humanidad. Por tal razón, la movilidad en la que vivimos nos invita a ser flexibles en la forma en que pensamos, aceptamos nuevos conocimientos, nos abrimos al mundo. Entre esos cambios se encuentra la tendencia a ser más prácticos y rebeldes. Queremos que nos sugieran y nos guíen, mas no que nos impongan y limiten.

Ahora bien, ¿Estamos transmitiendo en la escuela esta incapacidad y esta pereza a los estudiantes, quienes, a su vez sorprenden y desilusionan a los docentes? En muchas ocasiones, ya sea por el deseo de los docentes de mimetizarse con la practicidad de las nuevas generaciones, o por sus propias falencias y desinterés, sí se está promoviendo el facilismo y la mediocridad. La culpa de estas debilidades se traslada de las universidades a los colegios y a las familias; y los maestros caemos en una encrucijada que no ayuda a nuestro país a reivindicar su historia, su cultura, su identidad que poco a poco se van perdiendo en los textos no leídos y no escritos.

Después de intentar la respuesta a estos dos interrogantes y tratar, tal vez más por intuición que por razón, de explicar el por qué de esta encrucijada, veo la necesidad de terminar con otras dos preguntas que, más que seguir reflexionando nos proponen actuar: en un país castrado en términos de lectura y escritura ¿cómo se pueden estimular de manera auténtica, significativa y no excluyente estas dos competencias? ¿Vamos a seguir quejándonos y preocupándonos, o nos vamos a empezar a ocupar de estas falencias y realidades? "Ante los datos no caben lamentos catastróficos sino tareas inmediatas. .. lo que muestra la encuesta es un país lleno de retos". (Las Tramas de la Cultura. Rey, 2008).

\section{Bibliografía}

1. Albalat, A. (1961). El Arte de Escribir. Argentina: Editorial Atlántida.

2. Alfonso, I. (1999). Un Mensaje para Quienes Escribir es algo Insignificante. Acimed.

3. Asa Briggs, P. B. (2005). De Gutember a Internet. Buenos Aires, Argentina: Taurus.

4. Barthes, R. (1991). El Grado Cero de la Escritura. México: Siglo XXI Editores.

5. Derrida, J. (1998). Lingüística y Gramatología I. México: Siglo XXI Editores.

6. Freire, P. (1991). La Importancia de Leer y el Proceso de Liberación. México: Siglo XXI Editores.

7. Galina, I. (2002). La Lectura en la Era Digital. Biblioteca Universal Nueva Época, v. 5, n.1 p.1 enero-junio 2002

8. Martín Barbero, J. (2009, Mayo). Consumo Cultural, Clave. Lecturas, El Tiempo. pp. 12, 13.

9. Martín Barbero, J. (2002). Oficio de Cartógrafo. Santiago, Chile: Fondo de Cultura Económica. 
10.Martín Vivaldi, G. y Sánchez, A. (2000) Curso de Redacción: Teoría y Práctica de la Composición y del Estilo. España: International Thomson Editores

11. Petit, M. (2003). Nuevos Acercamientos a los Jóvenes y la Lectura. Méjico: Fondo de Cultura Económica

12. Rey, G. (2008). Las Tramas de la Cultura. Colombia: Convenio Andrés Bello.

13.Ricoeur, P. (1987) Tiempo y Narración I. Configuración del Tiempo en el Relato Histórico. Madrid: Cristiandad

14. Seco, R. (1973). Manual de Gramática Española. La Habana: Editorial Pueblo y Educación, Instituto Cubano del Libro.

15. Wells, G. (1989). Language in the Classroom: Literacy and Collaborative Talk. Language and Education, v3 n4 p251-73

\section{Consultas en línea}

1. Banguero, Sandra. (n.d.) Los Niños Necesitan Maestros que Lean y Escriban Bien. Ciencia al Día. Obtenida el 4 de marzo de 2011, de: http://aupec.univalle.edu.co/ informes/feb99/lectura.html

2. Bechara, E. (2009). Colombia: ¿Un País de Lectores? Obtenida el 18 de enero de 2011, de: http://www.eltiempo.com/blogs/el_tablero/2009/03/segundas-conclusionesal-artic.php

3. Colville, L. (2009) ¿Qué está pasando con la escritura? Obtenida el 6 de agosto de 2010, de: http://www.encontrandodulcinea.com/articulos/2009/Septiembre-/Qu--est--pasando-con-la-escritura-.html

4. Deleuze, G. (2011). La Lectura como Búsqueda de Intensidades. Impresiones Vivas. Obtenida el 20 de enero de 2011, de: http://impresionesvivas.blogspot. com/2010/11/deleuze-gilles-la-lectura-como-busqueda.html

5. González, S. La Escritura en la Escuela (n.d.) Obtenida el 2 de agosto de 2010, de: http://www.educar.org/articulos/escritura.asp

6. Montealegre, A. (2006) Escribir en la Universidad. Obtenida el 14 de julio de 2010, de : http://diariodelprofe.blogspot.com/2006/03/escribir-en-la-universidad.html

7. Romero, F. La Escritura en los Universitarios (n.d.) Obtenida el 2 de agosto de 2010, de: http://www.utp.edu.co/ chumanas/revistas/revistas/rev21/romero.htm

8. Samper, D. (2010). La Lectura Tiene Competidores Facilones. Altus en Línea, Unversidad Sergio Arboleda. Año 5 No. 7. Obtenida el 19 de enero de 2010, de: http://www.usergioarboleda.edu.co/altus/entrevista_daniel-samper.htm 